\title{
The development and validation of an acculturation scale: An empirical study based on experimental data
}

\author{
J.Q. Zhu and H. Li $i^{* 1}$ \\ School of Economics and Business Administration, Beijing Normal University, Beijing, China \\ *To whom all correspondence should be addressed \\ lihai@bnu.edu.cn
}

\begin{abstract}
Based on a review of existing acculturation models, an adjusted acculturation model was proposed in this study and a scale for measuring an acquirer's acculturation strategy was developed. We designed an experiment to collect data to validate this scale. Using CR values, CITC and EFA, we examined the scale items, and using Cronbach's alpha and the AVE method, we tested the scale's reliability, convergent validity, and discriminant validity. Finally, taking resistance to change as a criterion, we tested the scale's criterion-related validity. The results show that the scale has good measurement properties.
\end{abstract}

\section{Introduction}

The constant development of global economic integration drives Chinese enterprises to more quickly integrate themselves into the world market. Meanwhile, the sustained, steady and rapid development of the domestic economy makes the need for Chinese enterprises to engage in crossborder mergers and acquisitions become increasingly strong. Cross-border mergers and acquisitions have mainly served as a means for foreign investment and the rapid expansion of Chinese enterprises. Many enterprises, such as Lenovo, GEELY, Haier, TCL and CNPC, go abroad for cross-border mergers and acquisitions. However, many cross-border mergers and acquisitions fail. Less than two years after the BOE merged with HYDIS in 2005, the BOE revealed the significant loss of 1.368 billion yuan (Liu \& Jian, 2007). Only eight months after the TCL had merged with Alcatel in April 2007, both sides declared failure (Jiang \& Xiang, 2007). The phenomenon of 70/70 in mergers and acquisitions suggests that 70 percent of mergers and acquisitions fail to achieve the desired business value, and 70 percent failures are due to acculturation after mergers and acquisitions (Zhuang \& Tang, 2007). Acculturation refers to culture change that result from continuous, first-hand contact between two distinct cultural groups (Berry, 1997; Berry, Kim, Minde \& Mok, 1987). There are many ways to acculturate. An acculturation model means that a company chooses a certain way to solve the contradiction arising from direct contact (Peng, 2008). An appropriate acculturation model is helpful for the acculturation of both sides in mergers and acquisitions.

At present, researches on acculturation models mainly are conducted in the field of anthropology. Scales of acculturation are used to measure the acculturation models of immigrants. For example, the ARSMA scale (Cuellar, Arnold \& Maldonado, 1995; Cuellar, Harris \& Jasso, 1980), SL-
ASIA scale (Suinn, Ahuna \& Khoo, 1992), BAS scale (Marín \& Gamba, 1996) and KAS scale (Lim, Heiby, Brislin \& Griffin, 2002) are used to measure the acculturation models of Mexican immigrants, Asian immigrants, Hispanic immigrants and Khmer immigrants respectively. In the field of cross-border mergers and acquisitions, the lack of a measurement tool hinders the development of the empirical study of acculturation.

Can acculturation models and measurement tools for immigrants be directly used in the field of cross-border mergers and acquisitions? There is an important difference between the acculturation of immigrants and that of crossborder mergers and acquisitions. Immigrants are at a disadvantage in politics, the economy, the number of members, social status and culture, etc., and therefore, they must adapt to the culture of the dominant society. However, in cross-border mergers and acquisitions, the acquirer may be at a disadvantage in the number of employees and culture and usually assigns few managers to work in the acquired company, but the acquirer is at an advantage in terms of shareholding and management authority. In addition, the decision-maker and actor of acculturation are individuals in the context of immigrants, but the decision-maker and actor of acculturation are companies in cross-border mergers and acquisitions. Thus, these actors operate on different levels. We believe that the acculturation model and measurement tool for immigrants cannot be used directly in cross-border mergers and acquisitions.

Therefore, we attempt to answer the following question: How can we measure the acculturation model of the acquirer? Based on previous research, we propose an adjusted acculturation model of the acquirer, develop a scale for measuring the acquirer's acculturation strategy and validate the scale. 


\section{Review of existing research}

The study of acculturation models stems from anthropology and sociology. It evolved from the unidimensional model to the bidimensional model and from unilateralism to the interaction between both sides.

\section{The unidimensional acculturation model}

The unidimensional acculturation model argues that immigrants will completely accept the culture of the dominant society and will ultimately lose their own culture as time goes on (Gordon, 1964). This theory is criticized by many scholars. Berry (1983) noted that immigrants may not be assimilated by the dominant society, and the final acculturation form of the two groups may not be assimilation. Song, Hofstetter, Hovell, Paik, Park, Lee and Irvin (2004)measured the acculturation model of Korean immigrants in the United States, and the result showed that $79.4 \%$ of Korean immigrants retained their own culture, $14.7 \%$ of them adopted a hybrid culture, and only $5.9 \%$ of them accepted the culture of the dominant society.

\section{The bidimensional acculturation model}

\section{The acculturation model by Berry}

The bidimensional acculturation model, first proposed by Berry $(1983,1984)$, argued that the acculturation strategy of immigrants could be differentiated by two following issues: the first issue questions whether it is considered to be of value to maintain cultural identity and characteristics, and the second issue questions whether it is considered to be of value to maintain relationships with other groups. Four acculturation strategies are formed according to these two issues: assimilation, integration, separation and marginalization (see Figure 1). Assimilation is defined as the notion that an individual does not wish to retain his/her culture and seeks daily interaction with the dominant culture. The original culture is assimilated by the dominant culture. Integration is defined as the notion that an individual both retains his/her original culture and seeks daily interactions with the dominant society. Separation is defined as the notion that one individual holds onto and develops his/her own original culture and at the same time avoids interaction with the dominant society and hopes to exist as an independent individual. Marginalization is defined as the notion that one individual does not wish to retain his/her culture and avoids interactions with the dominant society. The group and its members experience confusion and anxiety, lose their identity and feel alienated (Berry, 1983, 1984).

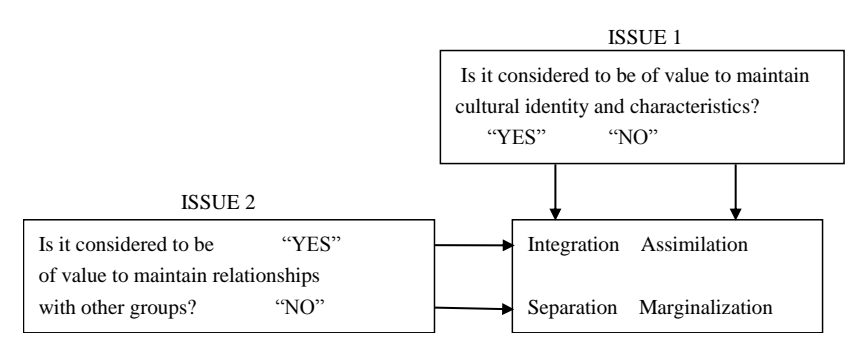

Figure 1: Acculturative models of a non-dominant group

Source: Berry, J.W., Kim, U., Minde, T. and Mok, D. (1987)

The acculturation model developed by Berry is supported by many empirical studies by various scholars. The survey by Alkhazraji, Gardner, Martin and Paolillo (1997) showed that among 277 Muslim immigrants, 113 participants (40.8\%) adopted an integration strategy, 101 participants $(36.5 \%)$ adopted a separation strategy, 21 participants (7.6\%) adopted a marginalization strategy, and 6 participants $(2.2 \%)$ adopted an assimilation strategy. The rest (13\%) did not show that they adopted any acculturation strategy. The survey by Cuellar et al. (1995) showed that among the immigrants surveyed, $43.5 \%$ of the participants adopted an integration strategy, $16.1 \%$ of the participants adopted a separation strategy, $13 \%$ of the participants adopted an assimilation strategy, and $10.3 \%$ of the participants adopted a marginalization strategy. The rest (18\%) did not show that they adopted any acculturation strategy.

The acculturation model proposed by Berry is the basis of bidimensional acculturation models and is one of the most influential theories in the field of acculturation. However, Berry studied the acculturation model mainly from the perspective of a "non-dominant" group, neglecting the influence of the dominant group on the acculturation.

\section{The interactive acculturation model by Bourhis}

The interactive acculturation model includes the three following parts: the acculturation model of the non-dominant group, the acculturation model of the dominant group and the interaction between the models of two groups (Bourhis, Moïse, Perreault \& Senecal, 1997).

The interactive acculturation model has the following two main contributions. First, the acculturation model of the dominant society is proposed. Five acculturation strategies are formed by two dimensions. These two dimensions are defined by the following questions: Do you find it acceptable that immigrants maintain their cultural heritage? Do you accept that immigrants adopt the culture of their host community? The five acculturation strategies are assimilation, integration, separation, exclusion and individualism. Second, the interaction of the acculturation model between the dominant society and the immigrant is considered. The degree that the acculturation model matches the dominant society and immigrants produces different outcomes. When the match is more congruent, it is easier for the two sides to achieve consensus, and the situation is more 
conducive to acculturation. The theory developed by Bourhis has made great progress in the field of acculturation. It takes into account not only the acculturation model of the dominant society but also the interaction of the acculturation model between the dominant society and immigrants.

\section{The relative acculturation extended model by Navas}

In anthropology, the latest development of the acculturation model is the relative acculturation extended model (RAEM) (Navas, García, Sánchez, Rojas, Pumares \& Fernández, 2005). This model synthesizes the research of Berry and Bourhis, making a distinction between the ideal and real situation of the acculturation of both immigrants and the dominant society and considering the various domains of sociocultural reality in which different acculturation strategies may be adopted by immigrants and the dominant society. Immigrants are more likely to adopt an integration or even an assimilation strategy in more materialistic domains (e.g., work and economic situations), whereas in more ideological domains (e.g., religious beliefs and values), they are more likely to adopt a separation strategy. This idea represents a great extension of previous theories; thus, its explanatory power is stronger.

\section{The acculturation model in management}

The acculturation model was first introduced into management by Nahavandi and Malekzadeh (1988) to analyse the acculturation in mergers and acquisitions. They argued that the factors affecting the acculturation model of the acquired company include the degree to which members aim to preserve their own culture and organizational practices and the degree to which they are willing to adopt the acquirer's culture and practices. Acculturation strategies are differentiated by these two dimensions. The factors affecting the acculturation model of the acquirer company include the degree to which the firm is multicultural and the diversification strategy. The latter mainly refers to the business relevance between the acquirer and the acquired company. Additionally, the authors noted that when the selected acculturation strategy of both sides was more congruent, the acculturative stress was lower and the merger was more likely to succeed.

Elsass and Veign (1994) analysed acculturation within mergers and acquisitions by utilizing Lewin's force-field approach. The authors argued that cultural differentiation was viewed as a restraining force and organizational integration was viewed as a driving force by which the acculturation strategy was differentiated. The authors also noted that the process of acculturation was dynamic and changed as the restraining forces and driving forces varied.

\section{The adjusted acculturation model of the acquirer}

The development of the acculturation scale is based on the acculturation model. However, we argue that there are two questions that arise regarding the existing acculturation model.
First, the relationship between influencing factors and the acculturation model is not stable, which leads to weak theoretical explanatory power. For example, according to the acculturation model by Nahavandi and Malekzadeh (1988), the acquirer, whose business relevance is strong with the acquired company, will adopt an integration or assimilation strategy. However, this sequence is not often what occurs in reality. GEELY merged with Volvo in 2010. Both companies belong to the automobile industry, and business relevance is strong, but GEELY adopted a separation strategy (Li, 2012; Liu \& Yan, 2011).

Second, marginalization or deculturation may be possible in the context of international immigrants, but it is impossible for firms to adopt such a negative strategy. In fact, marginalization or deculturation is a type of state, not a strategy. We reason that the firm is more likely to adopt a positive innovative strategy to achieve desired performance when the firm neither implements the acquirer's culture nor retains the acquired culture.

Third, acculturation refers to culture change that result from continuous, first-hand contact between two distinct cultural groups (Berry, 1997; Berry et al., 1987). According to the definition, the essence of acculturation is culture change, which should be the standard by which different strategies are distinguished.

Based on the foregoing discussion, we use the two dimensions of "implementing the acquirer's culture" and "retaining the acquired culture" to divide the acculturation model into four strategies. These strategies are assimilation, integration, separation and innovation (Li, 2012), as shown in Figure 2.

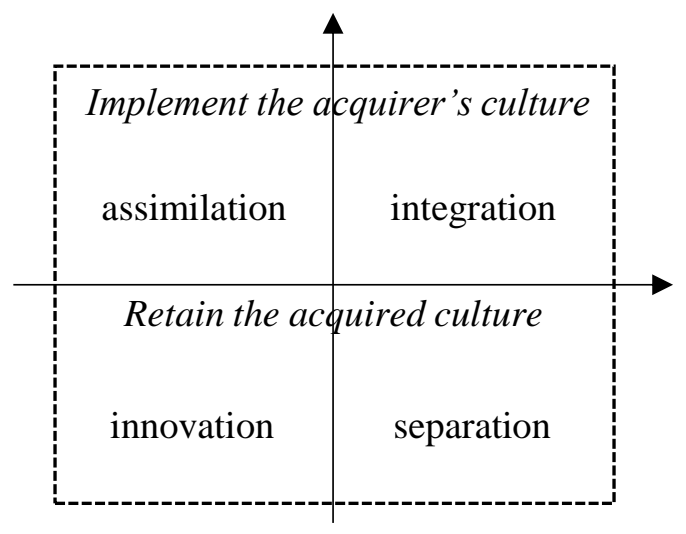

Figure 2: Acculturation model

Source: Li, H. (2012)

Assimilation is defined as the notion that the firm vigorously implements its own culture but rarely retains the acquired culture. Integration is defined as the notion that the firm not only implements its own culture but also retains the acquired culture and tries to integrate the cultural advantages of both sides. Separation is defined as the notion that the acquirer does not intervene in the acquired culture and does not 
implement its own culture in the acquired firm but retains the acquired culture. Innovation is defined as the notion that the acquirer seeks a new culture to replace the original culture of both sides.

The degree that the acquirer implements its culture or retains the acquired culture depends on the degree of identification with his/her own culture. When the degree of identification is higher, the culture is felt more strongly, whereas the acquirer is apt to implement its own culture; however, it is difficult for the acquired firm to change its culture, and the acquired firm is apt to retain its own culture.

Therefore, an acculturation strategy is the result of balance. The acquirer evaluates his/her own culture and the acquired cultural identification and the difficulty of culture change to choose a strategy. For example, Lenovo adopted an integration strategy after it had merged with IBM PC but adopted an assimilation strategy after it had merged with CCE in Brazil (Wang, 2013). The reason for this difference is that the cultural identification of IBM's employees is higher than that of CCE's employees. As previously mentioned, GEELY adopted a separation strategy. The reason why this strategy was adopted is that Volvo is held in very high regard in Sweden, and the cultural identification of employees is high and very difficult to change.

\section{Items}

In this study, 14 items were generated based on previous organizational culture scales. Then, the 14 items were repeatedly reviewed at the meeting of acculturation in mergers and acquisitions. The judges included an associate professor of organizational culture, three graduate students majoring in organizational culture and five part-time MBA students with experience in cross-border mergers and acquisitions. Finally, seven items were used to measure the acculturation model.

The seven items include "the management style of company after a merger, such as the extent of participation in decisionmaking or regularization," "the reward system of a company after a merger," "the evaluation system of a company after merger," "the standard of measuring success after a merger, such as the market share, employee satisfaction, sales, profit or customer satisfaction," "the business process of a company after a merger, such as recruiting, promotion or reimbursement, and so on," "the core value of a company after a merger," and "the vision and long-time goal of a company after a merger." The first three items are derived from the organizational culture scale developed by Datta (1991). The fourth item is derived from the OCAI scale developed by Quinn and Cameron (1998). Meeting attendants generated the last three items.

Four options are provided for every item with reference to the OCAI scale by Quinn and Cameron (1998). For example, the four options of "the management style of a company after a merger" are "A. implement the acquirer's management style," "B. simultaneously implement both sides' management style," "C. retain the acquired management style," and "D. implement a new management style on the basis of integrating both sides' management style." These options are used to measure assimilation, integration, separation, and innovation strategy. The final scale includes seven items, and four options are provided for every item.

\section{Method}

We designed an experiment to collect data because it is difficult to collect practical data concerning acculturation in cross-border mergers and acquisitions. We designed four scenarios to make participants perceive the cultural identification of both sides in mergers and acquisitions; then, the acquirer chose an acculturation strategy. The extent of the acquired side's resistance to change varied with the acculturation strategies adopted.

\section{Experimental design}

We used a $2 \times 2$ between-group experimental design to design four scenarios according to seven items to simulate a high cultural identification and a low cultural identification of both sides. The scenario story is that a Chinese company merges with an American company and appoints Li Shuangliang, the merger manager, to the American company to address the acculturation of the two sides. In the story, according to the content of seven items, we describe Li's cultural identification with his own company culture and the American company's employees' cultural identification with their own company culture as perceived by Li.

In the first scenario, the story reflects that Li's cultural identification with his own company culture is high, and he perceives that the American company's employees' cultural identification with their own company is low. In the second scenario, the story reflects that Li's cultural identification with his own company culture is high, and he perceives that the American company's employees' cultural identification with their own company is high. In the third scenario, the story reflects that Li's cultural identification with his own company culture is low, and he perceives that the American company's employees' cultural identification with their own company is high. In the fourth scenario, the story reflects that Li's cultural identification with his own company culture is low, and he perceives that the American company's employees' cultural identification with their own company is low.

During the experiment, every group included two students, one of whom played the part of $\mathrm{Li}$, the merger manager, and the other played the part of Jack, an employee of the acquired American company. Every group randomly accepted one scenario story and filled out the acculturation questionnaire. The numbers of participants in the four scenario groups were 27, 24, 25 and 26. The questionnaire featured two parts. One part, called the Li Questionnaire, was filled out by the student playing the part of $\mathrm{Li}$, and the other, called the Jack Questionnaire, was filled out by the other student playing the part of Jack. First, the student playing the part of Li was asked 
to carefully read the scenario story and suppose that he was $\mathrm{Li}$ in the story and then respond to the following items in the Li Questionnaire: Li's cultural identification with his own company culture, the perceived cultural identification of the American company's employees with their own company culture and seven items of the acculturation scale. The $\mathrm{Li}$ Questionnaire was divided into two questionnaires. Questionnaire 1 included the scenario story and cultural identification items, and Questionnaire 2 included seven items of the acculturation scale. After Questionnaires 1 and 2 were completed, Questionnaire 2 was given to the other student playing the part of Jack in the same group.

Next, the student playing the part of Jack inferred what acculturation measures $\mathrm{Li}$ would take according to Questionnaire 2. For example, in terms of the management style, will Li implement the Chinese company's management style, simultaneously implement both sides' management styles, retain the American company's management style, or implement a new management style based on the integration of both sides' management styles? Then, the student filled out the Jack Questionnaire to answer to what extent he/she resisted the measures taken by $\mathrm{Li}$.

\section{Sample}

The study sample consisted of 214 MBA students from business school in Beijing. Questionnaires were delivered and filled out immediately during class. In total, 107 pairs of questionnaires were delivered, and 102 pairs of valid questionnaires were ultimately included in this study, with a validity rate of $95.3 \%$. With respect to the total number of participants, employees accounted for $33.8 \%$, middle managers accounted for $59.3 \%$, top managers accounted for $5.4 \%$, and others did not report. Females accounted for $43.1 \%, 58.8 \%$ of the participants are married, and $8.3 \%$ had experience with cross-border mergers and acquisitions. The average age of the participants was $31(S D=5.69)$.

\section{Measure}

The acculturation model was measured through seven items developed in this study, and four options were provided for every item to measure assimilation, integration, separation, and innovation.
The resistance to change was measured through a five-item scale developed by Oreg (2006). A sample item was "I protest the change." The scale was a seven-point Likert-type scale.

\section{Analysis}

We used SPSS17.0 to analyse the data. The manipulation, items, reliability and validity were tested. First, the manipulation was tested by an independent-samples t-test. Second, using CR values, CITC and EFA, we examined the scale items, and using the AVE method, we tested the scale's convergent validity and discriminant validity. Finally, we tested the criterion-related validity by ANOVA.

\section{Results}

\section{Manipulation testing}

We manipulated two variables "the acquiring employees' cultural identification with their own company culture" and "the acquired employees' cultural identification, perceived by the acquiring employees, with their own company culture." The results of the t-test showed that the mean difference in the acquiring employees' cultural identification between the highest and the lowest was significant $\left(\mathrm{M}_{\text {high cultural identification }}=\right.$ $\left.5.470, \mathrm{M}_{\text {low cultural identification }}=2.270, \mathrm{t}_{(102)}=18.174, p<0.001\right)$, and the mean difference in the acquired employees' cultural identification as perceived by the acquiring employees between the highest and the lowest was significant $\left(\mathrm{M}_{\text {high }}\right.$ perceived cultural identification $=4.960, \mathrm{M}_{\text {low perceived cultural identification }=}$ $\left.2.080, \mathrm{t}_{(102)}=17.264, p<0.001\right)$. These results demonstrated that the manipulation was successful.

\section{Items}

We sifted the items by CR values, CITC and EFA.

First, the total scores of the four acculturation strategies were computed. Then, we tested the significance of the CR value of every item by an independent-sample t-test (Wu, 2000). The results are shown in Table 1 . The CR values of each strategy's items were significant $(P<0.001)$. Therefore, all items were retained.

As shown in Table 1, the CITC values of each strategy's items were greater than 0.4 . Therefore, all items were retained. 
Table 1. CR values, CITC values and EFA

\begin{tabular}{|c|c|c|c|c|c|c|c|c|c|c|c|c|c|c|c|}
\hline \multicolumn{4}{|c|}{ Assimilation } & \multicolumn{4}{|c|}{ Integration } & \multicolumn{4}{|c|}{ Separation } & \multicolumn{4}{|c|}{ Innovation } \\
\hline Items & $\begin{array}{c}\mathrm{CR} \\
\text { value }\end{array}$ & $\begin{array}{l}\text { CITC } \\
\text { value }\end{array}$ & $\begin{array}{l}\text { Factor } \\
\text { loading }\end{array}$ & Items & $\begin{array}{c}\mathrm{CR} \\
\text { value }\end{array}$ & $\begin{array}{l}\text { CITC } \\
\text { value }\end{array}$ & $\begin{array}{l}\text { Factor } \\
\text { loading }\end{array}$ & Items & $\begin{array}{c}\mathrm{CR} \\
\text { value }\end{array}$ & $\begin{array}{l}\text { CITC } \\
\text { value }\end{array}$ & $\begin{array}{l}\text { Factor } \\
\text { loading }\end{array}$ & Items & $\begin{array}{c}\text { CR } \\
\text { value }\end{array}$ & $\begin{array}{l}\text { CITC } \\
\text { value }\end{array}$ & $\begin{array}{l}\text { Factor } \\
\text { loading }\end{array}$ \\
\hline A1 & 0.000 & 0.612 & 0.638 & B1 & 0.000 & 0.718 & 0.762 & $\mathrm{C} 1$ & 0.000 & 0.798 & 0.848 & D1 & 0.000 & 0.616 & 0.662 \\
\hline A3 & 0.000 & 0.756 & 0.791 & B3 & 0.000 & 0.725 & 0.783 & $\mathrm{C} 3$ & 0.000 & 0.804 & 0.848 & D3 & 0.000 & 0.800 & 0.869 \\
\hline A4 & 0.000 & 0.722 & 0.764 & B4 & 0.000 & 0.781 & 0.846 & $\mathrm{C} 4$ & 0.000 & 0.781 & 0.822 & D4 & 0.000 & 0.660 & 0.697 \\
\hline A5 & 0.000 & 0.793 & 0.836 & B5 & 0.000 & 0.686 & 0.734 & $\mathrm{C} 5$ & 0.000 & 0.616 & 0.648 & D5 & 0.000 & 0.708 & 0.761 \\
\hline A7 & 0.000 & 0.777 & 0.822 & B7 & 0.000 & 0.568 & 0.602 & $\mathrm{C} 7$ & 0.000 & 0.653 & 0.688 & D7 & 0.000 & 0.653 & 0.675 \\
\hline \multicolumn{3}{|c|}{ Eigenvalue } & 4.709 & & & & 4.202 & & & & 4.560 & & & & 4.332 \\
\hline \multicolumn{3}{|c|}{$\%$ Variance explained } & 67.271 & & & & 60.024 & & & & 65.145 & & & & 61.887 \\
\hline
\end{tabular}

Because the four acculturation strategies are not four dimensions of a single construct but are four different constructs, we conducted EFA to test items for every acculturation strategy. The results showed that the KMOs of the four strategies were greater than $0.85\left(\mathrm{KMO}_{\text {assimilation }}=\right.$ $0.874, \mathrm{KMO}_{\text {integration }}=0.869, \mathrm{KMO}_{\text {separation }}=0.875, \mathrm{KMO}_{\text {innovation }}$ $=0.850)$, and Bartlett's tests were significant $(p<0.001)$, which showed that it was appropriate to conduct EFA. The principal components method was used, and the factors with eigenvalues greater than 1 were extracted. The results are shown in Table 1. One factor was extracted for each strategy, and the percent of variance explained was greater than $60 \%$. The standardized factor loadings of all items ranged between 0.602 and 0.869 . Therefore, all items were retained.

Finally, all items stood the test regarding CR values, CITC and EFA and were retained.

Table 2. Correlation coefficients and AVE among variables

\begin{tabular}{lcccc}
\hline & Assimilation & Integration & Separation & Innovation \\
\hline Assimilation & $(0.620)$ & & & \\
Integration & 0.207 & $(0.536)$ & $(0.596)$ & $(0.558)$ \\
Separation & -0.051 & 0.467 & 0.004 & \\
Innovation & -0.221 & 0.088 & &
\end{tabular}

Note: AVE is presented on the diagonal.

\section{Discriminant validity}

Testing whether the AVE values of all variables are greater than the square of the correlation coefficients among the variables is the most frequently used method to test discriminant validity (Fornell \& Larcker, 1981). Table 2 shows that the maximum correlation coefficient between separation and integration was 0.467 , the square of which is $0.218(0.467 * 0.467)$. This coefficient was less than the minimum value of AVE (0.536). Therefore, the AVE values among all variables were greater than the square of the correlation coefficients among all variables. The discriminant validity of the four acculturation strategies was good, which demonstrated that the scale can differentiate between the four acculturation strategies.

\section{Criterion-related validity}

Criterion-related validity is defined as the degree of correlation between the scale used and an external criterion.

\section{Reliability}

The results of reliability testing showed that Cronbach's alpha values for assimilation, integration, separation and innovation were $0.917,0.887,0.910$ and 0.896 , respectively, all of which were greater than 0.7 . Therefore, the reliability was good.

\section{Convergent validity}

Fornell and Larcker (1981) suggested that the average variance extracted (AVE) was a good convergent validity indicator of one latent variable estimated by a group of observed variables. An AVE greater 0.5 indicated that the convergent validity of the latent variables was good (Qiu \& Lin, 2009). As shown in Table 2, the AVE of the four strategies was greater than 0.5 , which showed that the convergent validity of the four strategies was good. 
Table 3. Results of ANOVA

\begin{tabular}{|c|c|c|c|c|c|c|c|}
\hline $\begin{array}{l}\text { Criterion-related } \\
\text { variable }\end{array}$ & $\begin{array}{c}\text { Total mean } \\
(\mathrm{N}=100)\end{array}$ & $\begin{array}{l}\text { Assimilation } \\
(\mathrm{N}=27)\end{array}$ & $\begin{array}{l}\text { Integration } \\
(\mathrm{N}=23)\end{array}$ & $\begin{array}{c}\text { Separation } \\
(\mathrm{N}=24)\end{array}$ & $\begin{array}{l}\text { Innovation } \\
(\mathrm{N}=26)\end{array}$ & $\mathrm{F}$ & Sig \\
\hline $\begin{array}{ll}\begin{array}{l}\text { Resistance } \\
\text { change }\end{array} & \text { to } \\
\text { chas }\end{array}$ & 3.747 & 3.313 & 4.017 & 4.245 & 3.500 & $3.746 *$ & 0.014 \\
\hline
\end{tabular}

Note : * $\mathrm{P}<0.05, * * \mathrm{P}<0.01, * * * \mathrm{P}<0.001$.

\section{Discussion}

At present, cross-border mergers and acquisitions have mainly constituted a means for foreign investment and the rapid expansion of Chinese enterprises. The size of Chinese companies' cross-border mergers and acquisitions has recently become increasingly large. Acculturation is very important for cross-border mergers and acquisitions. The existing acculturation strategies are different from the influencing factors and do not highlight the features of the acculturation strategies themselves. In this study, we proposed a more distinct and more practical acculturation model based on the features of the acculturation strategies themselves, which is one of the main contributions of this study.

There is no effective measurement tool to measure the acculturation model, and the lack of this scale undoubtedly hinders the development of study on the acculturation model in cross-border mergers and acquisition. Another main contribution of this study is the development of a suitable scale for measuring the acculturation model in cross-border mergers and acquisitions. Using CR values, CITC and EFA, we examined the scale items. The resulting Cronbach's alpha showed that the reliability of this scale was good, and the AVE values obtained showed that the convergent validity and discriminant validity were good. The results of an ANOVA of the resistance to change showed that the criterion-related validity of this scale was good. Finally, the results showed that the scale exhibits good measurement properties. Thus, the scale can serve as the operational basis on which to study the acculturation model and is helpful for quantitative research.

The limitations of this study are the following: the data were collected using an experimental method. There may be differences in employees' cultural identification and perceptions between experiment and practice. Another limitation is that the generalizability of this study's conclusions is limited because the sample used was composed of MBA students. The scale should be further tested and improved with a sample of cross-border mergers and acquisition companies in future research. In addition, future research should further explore the relationship between the acculturation strategy used and the performance of mergers and acquisitions as well as the mechanisms and boundaries of acculturation strategies.

\section{References}

Alkhazraji, K.M., Gardner, W.L., Martin, J.S. \& Paolillo, J.G.P. 1997. 'The acculturation of immigrants to US organizations', Management Communication Quarterly, 11(2): 217-65.
Berry, J.W. 1983. Acculturation: A comparative analysis of alternative forms. In Samuda, R. J. \& Woods, S. L. (Eds.). Perspectives in immigrant and minority education. Lanham, MD: University Press of America.

Berry, J.W. 1984. Cultural relations in plural societies: Alternatives to segregation and their sociopsychological implications. In Miller, N. \& Brewer, M. B. (Eds.). Groups in contact. Orlando, FL: Academic Press.

Berry, J.W. 1997. 'Immigration, acculturation, and adaptation', Applied Psychology, 46(1): 5-34.

Berry, J.W., Kim, U., Minde, T. \& Mok, D. 1987. 'Comparative studies of acculturative stress', International Migration Review, 21(3): 491-511.

Bourhis, R.Y., Moïse, L.C., Perreault, S. \& Senecal, S. 1997. 'Towards an interactive acculturation model: A social psychological approach', International Journal of Psychology, 32(6): 369-86.

Cuellar, I., Arnold, B. \& Maldonado, R. 1995. 'Acculturation rating scale for Mexican Americans- II : A revision of the original ARSMA scale', Hispanic Journal of Behavioral Sciences, 17(3): 275-304.

Cuellar, I., Harris, L.C. \& Jasso, R. 1980. 'An acculturation scale for Mexican American normal and clinical populations', Hispanic Journal of Behavioral Sciences, 2(3): 199-217.

Datta, D.K. 1991. 'Organizational fit and acquisition performance: Effects of post-acquisition integration', Strategic Management Journal, 12(4): 281-97.

Elsass, P.M. \& Veiga, J.F. 1994. 'Acculturation in acquired organizations: A force-field perspective', Human Relations, 47(4): 431-53.

Fornell, C. \& Larcker, D.F. 1981. 'Evaluating structural equation models with unobservable variables and measurement error', Journal of Marketing Research, 18(1): 39-50.

Gordon, M.M. 1964. Assimilation in American life. Nueva York: Oxford University Press.

Jiang, T. \& Xiang, J. 2007. 'The research on cultural integration overseas mergers and acquisitions in China', Reform \& Opening, (5): 44-5.

Li, H. 2012. 'Acculturation, not cultural integration', PKU Business Review, (12): 74-9.

Lim, K.V., Heiby, E., Brislin, R. \& Griffin, B. 2002. 'The development of the Khmer acculturation scale', International Journal of Intercultural Relations, 26(6): 653-78.

Liu, X. \& Jian, M. 2007. 'How to upgrade technological capability through international acquisition: The case of BOE', China Soft Science Magazine, (12): 73-82. 
Liu, X. \& Yan, Y. 2011. 'The cultural integration of GEELY merging Volvo', Times Finance, (10): 84-5.

Marín, G. \& Gamba, R.J. 1996. 'A new measurement of acculturation for Hispanics: The bidimensional acculturation scale for Hispanics (BAS)', Hispanic Journal of Behavioral Sciences, 18(3): 297-316.

Nahavandi, A. \& Malekzadeh, A.R. 1988. 'Acculturation in mergers and acquisitions', Academy of Management Review, 13(1): 79-90.

Navas, M., García, M.C., Sánchez, J., Rojas, A.J., Pumares, P. \& Fernández, J.S. 2005. 'Relative acculturation extended model (RAEM): New contributions with regard to the study of acculturation', International Journal of Intercultural Relations, 29(1): 21-37.

Oreg, S. 2006. 'Personality, context, and resistance to organizational change', European Journal of Work and Organizational Psychology, 15(1): 73-101.

Peng, R. 2008. Research on cultural integration of corporate merger \& acquisition., Huazhong University of Science and Technology, Wuhan.

Qiu, H. \& Lin, B. 2009. The theory and application of structural equation model. Beijing: China Light Industry Press.

Quinn, R.E. \& Cameron, K.S. 1998. Diagnosing and changing organizational culture: Based on the competing values framework. New York: Addison-Wesley Press.

Song, Y.J., Hofstetter, C.R., Hovell, M.F., Paik, H.Y., Park, H.R., Lee, J. \& Irvin, V. 2004. 'Acculturation and health risk behaviors among Californians of Korean descent', Preventive Medicine, 39(1): 147-56.

Suinn, R.M., Ahuna, C. \& Khoo, G. 1992. 'The Suinn-Lew Asian self-identity acculturation scale: Concurrent and factorial validation', Educational and Psychological Measurement, 52(4): 1041-46.

Wang, J. 2013. The case study of Lenovo about cross-border cultural integration. Beijing Normal University, Beijing.

Wu, M.L. 2000. SPSS statistical applications practice. Beijing: China Railway Publishing House.

Wu, Z. \& Chen, F. 2011. 'The scale development of team psychological safety climate in Chinese cultural context', Chinese Journal of Management, 8(1): 73-80.

Zhang, O. \& Zhang, X. 2003. 'The review of cultural integration mergers and acquisition', Journal of Hunan Agricultural University (Social Sciences), 4(3): 39-42.

Zhuang, E. \& Tang, J. 2007. 'The cultural integration cross-border mergers and acquisitions: The case of GMAC SAIC merging SSANG YONG Motor Company', Market Modernization, (08): 297-98. 